\title{
LA SUPUESTA DAMA SEDENTE DEL CABECICO DEL TESORO (Verdolay, Murcia)
}

\author{
POR \\ MÓNICA RUIZ BREMÓN
}

\begin{abstract}
RESUMEN
Según la autora, la llamada Dama del Verdolay, una importante escultura en piedra del periodo clásico de la cultura ibérica, podría ser la imagen entronizada de un varón. Esta consideración se apoya en el estudio de su atuendo, identificado a través de otras imágenes masculinas ibéricas.
\end{abstract}

\section{SUMMARY}

According to the author, the so-called "Verdolay's L.ady", an important sculpture from the classic period of the Iberian Culture, could be an enthroned man's image. This assert is based in the study of its wore, identified by other male Iberians figures.

La pieza objeto de este estudio es de sobra conocida dentro de la plástica ibérica. Se trata de una estatua sedente, en piedra, procedente de la necrópolis del Cabecico del Tesoro (Verdolay, Murcia), que se conserva desde 1936 en el Museo Arqueológico Provincial de Murcia ' (figs. 1 y 3 ).

Dada la importancia de semejante testimonio para el conocimiento de la cultura ibérica y sus relaciones con el mundo colonial griego, me ha parecido del mayor interés acometer de nuevo su estudio, fruto del cual resulta una nueva interpretación de su significado.

Sobre la fecha y circunstancias concretas de su hallazgo me remito a las noticias que, en su dia, proporcionaron sus descubridores ${ }^{2}$ : apareció sobre la tumba número 114 de la cita-

${ }^{1}$ N.Inv.2737 y número de registro de la Colección del Cabecico del Tesoro 0/49. Desde aquí deseo hacer constar mi agradecimiento al Museo de Murcia por la ayuda facilitada para la realización de este trabajo.

${ }^{2}$ G. Nieto, «Noticia de las excavaciones realizadas en la Necrópolis Hispánica de Cabecico del Tesoro, Verdolay (Murcia)", BolSemEstudArteArq, 6, 1939-40, 137-160. Vid. La bibliografia general so- 
da necrópolis durante la primera campana de la excavación en el yacimiento. Los varios fragmentos que la formaban se hallaban dispersos por las proximidades de esta tumba y de la número $119^{3}$ al igual que parte de una cabeza (fig. 5). Esta fue considerada perteneciente a la estatua, por lo que, una vez realizada la oportuna restauración ${ }^{4}$, cabeza y cuerpo fueron expuestos conjuntamente en el Museo de Murcia (fig. 4).

Las razones para tal unión fueron expuestas por G. Nieto al publicar la primera noticia sobre la excavación en el Verdolay; si asi se procedió fue: "sin ninguna base en que apoyarnos, más que en una afinidad evidente en cuanto a proporciones y arte se refiere $)^{5}$. Tiempo después la cabeza fue separada del cuerpo, como más adelante veremo ${ }^{6}$. De momento, conviene un rápido recorrido sobre su historiografía, analizando las opiniones de quienes se ocuparon de ella, ya como figura completa, ya acéfala. Estas opiniones no sólo forman parte de la historia de la estatua, sino que, en cierto modo, también contienen las claves de su equivocada interpretación y de los problemas que, a mi parecer, aún hoy plantea.

Ya G. Nieto, al presentarla, hace un breve comentario sobre ella relacionándola con ejemplares del mundo arcaico y, por el tipo de peinado del fragmento de cabeza, con la esfinge del Cortijo del Álamo? . Pero es A. García y Bellido, en rigor, el primer estudioso de la pieza que nos ocupa ${ }^{8}$. Siguiendo idéntico criterio que sus descubridores, analiza cabeza y cuerpo como parte de un todo y propone los primeros paralelos formales para este "personaje, probablemente masculino». A juzgar por el tipo sedente y por el tocado - una cinta en torno a la cual se enrolla el cabello-, A. García y Bellido relaciona la estatua con el arte griego de la primera mitad del siglo $\mathrm{V}^{9}$, en lo que insiste en $1948^{10}$. Sin embargo, en 1954 y sin que conozcamos la causa directa, el autor pasa a considerar que la estatua en cuestión es una imagen femenina. Por esta razón la estudia como un testimonio más de dama ibérica sedente, junto a las figuras del Llano de la Consolación y del Cerro de los Santos ".

A partir de este momento la estatua del Cabecico del Tesoro, "una dama, sin ninguna duda" ${ }^{12}$, pasa a ser considerada, en virtud de su labra y por sus dimensiones, uno de los más destacados ejemplares de la estatuaria femenina sedente del arte ibérico ${ }^{13}$.

bre esta necrópolis y sus materiales en F. Quesada, Armamento, Guerrra y Sociedad en la necrópolis ibérica de "El Cabecico del Tesoro» (Murcia, España), B.A.R. International Series 502, 1989, I, 40-48.

${ }^{3}$ F. Quesada, op. cit., en nota 2,1, p. 118.

${ }^{4}$ La restauración tal y como indica G. Nieto ( La necrópolis hispánica del Cabecico del Tesoro, Verdolay (Murcia)». Crónica del III Congreso Arqueológico del Sudeste Español, Murcia, 1947, p. 178), fue llevada a cabo por Cayetano de Mergelina y Luna, autor, junto a A. Fernández de Avilés, director del Museo de Murcia entonces, de la primera campaña de excavación en el yacimiento.

${ }^{5}$ Op. cit. en nota 2, p. 142.

${ }^{6}$ Hacia finales de los años 50 , según se deduce de la bibliografía, ya que este dato no me ha podido ser facilitado po el Museo (Vid. Infra., notas 13 y 18).

7 Cifr.: J. M. Carriazo: «Esculturas hispánicas del Cortijo del Álamo», A.E.A. XX, 1931, 163-166.

${ }^{8}$ A. Garcia y Bellido: "Arte griego provincial. La figura sedente de Verdolay (Murcia)», A.E.A.. 14, 1940, 351.

${ }^{9}$ En concreto el autor propone las figuras sedentes femeninas de Mileto (G. M. A. Richter, $A r$ chaic Greek Art., Oxford, 1949, fig. 262) y de Samos en el Louvre y en el British, el Apolo del Museo de Nápoles, una cabeza del Museo Nacional de Atenas y el Apolo de Agrigento. (Op. cit. en nota 1, fig. 1c, 2b, 2c y 2d), los tres últimos masculinos y con "Rollenfrisur».

${ }^{10}$ "Archaelogical News. Spain and Portugal», A.J.A., 52, 1948, 241 ss.

1 "Arte ibérico», Historia de España (dirigida por R. Menéndez Pidal), I, 3. Madrid. 1954, p. 502-8.

12 Ibid.; p. 504.

${ }^{13}$ En este tiempo se suceden los estudios sobre escultura y arte ibéricos en general en los que aparece 
No comparte esta opinión F. Benoit, quien, en un estudio dedicado a la dama sedente de la Alcudia de Elche ${ }^{14}$, compara su actitud con la del "personaje sentado, sin duda un hombre, de Verdolay, procedente de la necrópolis de Cabecico del Tesoro (Santa Catalina del Monte) en el Museo de Murcia, cuyo peinado sujeto por una cinta, se ha inspirado en un original griego del siglo $\mathrm{V} »$. Sin embargo, para Benoit la actitud de esta figura es la misma que la de las diosas madres del arte arcaico griego.

Hasta aquí, todos los trabajos citados basan la interpretación de la estatua en el análisis de la postura sedente y, a efectos de cronología, en el estudio de la cabeza. Esta, ciertamente, presenta unos rasgos formales susceptibles de relacionar con el arte griego y, por ende, de ser fechada siquiera aproximadamente. El problema cambia de orientación cuando cabeza y cuerpo son separados en el Museo de Murcia ${ }^{15}$. El motivo: la convicción de que uno y otro son independientes, acercándose el primer fragmento a prototipos masculinos del arte griego y siendo en cambio el cuerpo un ejemplo más de dama entronizada entre los varios ya conocidos en la plástica mayor ibérica ${ }^{16}$.

En esta línea se inscribe el estudio monográfico que W. Trillmich dedica a la cabeza, pero que interesa especialmente por sus conclusiones de tipo cronológico al tema que tratamos ${ }^{17}$. Mediante el exhaustivo análisis de los paralelos formales de! «Rollenfrisur» y del tratamiento de los ojos, prácticamente lo único conservado de ella, Trillmich demuestra su vinculación formal con un prototipo masculino del arte severo griego. No incluye el estudio de la estatua sedente, limitándose a señalar, entre sus paralelos griegos más próximos, los procedentes del Mediterráneo occidental. Así, una figura de Demeter del Santuario de la Malophoros en Selinunte, la diosa de Tarento en Berlín y otras figuras de terracota procedentes de Gela, Paestum, Tarento, etc., son algunos de los ejemplos aducidos ${ }^{18}$. Pero por lo que respecta a la datación del fragmento de cabeza, Trillmich duda si situarlo cercano en el tiempo a sus modelos griegos del siglo $\mathrm{V}$ o, por el contrario, considerarlo obra del siglo IV, tal y como le induce a pensar el contexto arqueológico de la uecrópolis ${ }^{19}$.

Una vez admitido por la mayoría de los investigadores que cabeza y cuerpo son piezas independientes, que no pertenecieron nunca a la misma estatua, la preocupación primordial en los estudios dedicados a la figura de Verdolay se va a centrar, a partir de entonces, en

citada este pieza. Son algunos de ellos: A. Ramos Folques, "Museo de Murcia», MMAP, 1950-1; M. Jorge Aragoneses, "Museo Arqueológico de Murcia», Guías de los Museos de España, VI, 1956, p. 40: M. Camón Aznar, Las artes y pueblos de España, Madrid, 1954, p. 656. Los dos primerós son sendas relaciones de catálogos y adquisiciones del Museo de Murcia. En cuanto al tercero, presenta la novedad de indicar paralelos púnicos posteriores al siglo V. M. Jorge Aragoneses transmite por primera vez la idea de que la cabeza y cuerpo no se corresponden, aunque aún se encuentren unidos en el Museo.

14 «La Dama de Elche aux pavots», ArchPrehLev, 6, 1957, 149-152.

is A. Blanco, «Die klassischen Wurnzel der iberischen Kunst», MM 1, 1960, p. 115, nota. 35.

16 A. Arribas (The Iberians, Londres, 1963, p. 158-9) la considera la «mejor» de las figuras sedentes funerarias ibéricas, con paralelos en Didima y Mileto; A. García y Bellido (Iberische Kunst in Spanien, Mainz, 1971, p. 43, Lams. 60,61; Arte ibérico en España, Madrid, 1980 (reedición por A. Blanco) p. 56-57 (láms. 60 y 61) publica por separado las fotografías de la figura completa (fig. 61) y sólo de la cabeza (fig. 60).

17 «Ein Kopffragment aus Verdolay bei Murcia. Zur Problematik der Datierung iberischer Grossplastik aufgrund griechischer Vorbilder», M.M., 16, 1975, 208-245.

18 Ibid., p. 213, nota 17.

19 Ibid., p. 212 , p. 244-5. 


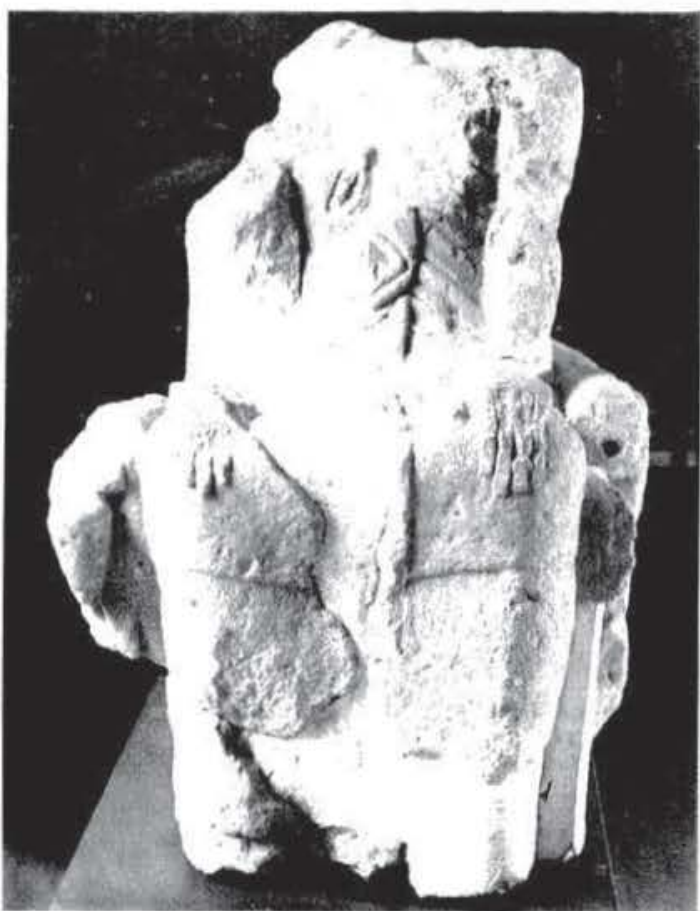

Figura 1. - Lstatua sedente en piedra de la necropolis iberica del Cabecico del Tesoro, Verdolay, Murcia. Vista frontal. Museo Arqueológico de Murcia.

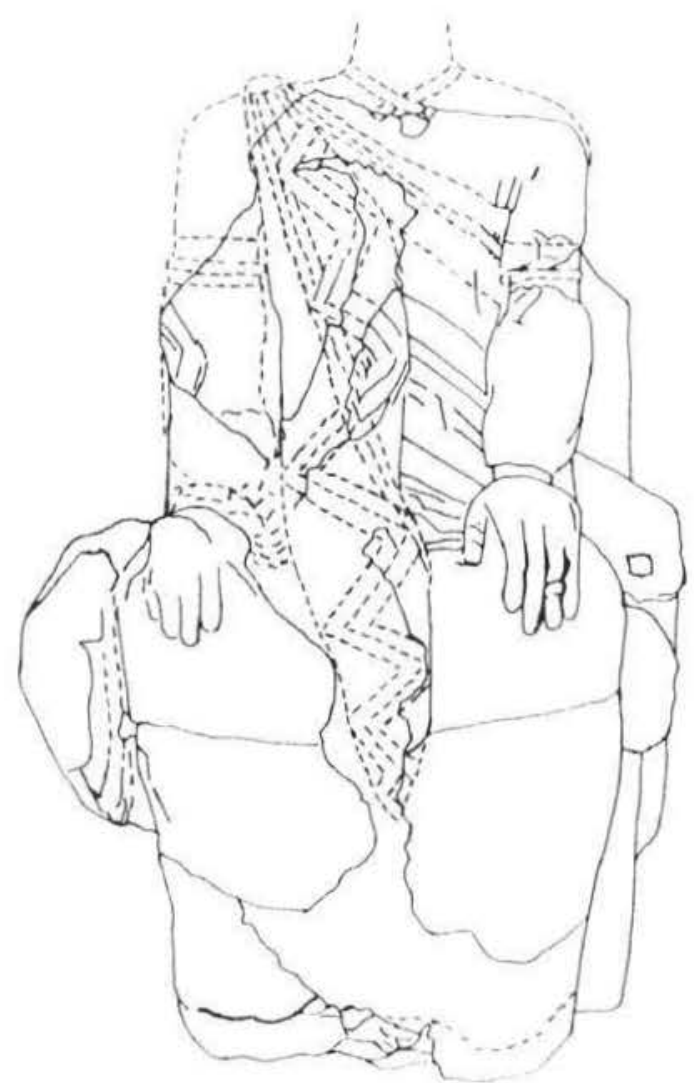

Figura 2.-Reconstitución hipotética del atuendo de la figura sedente de Verdolay.

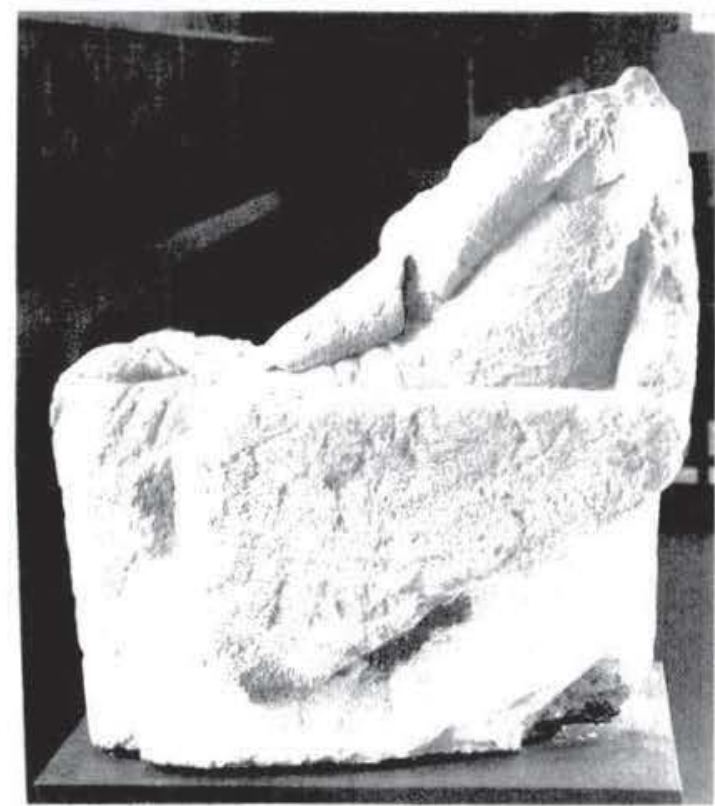

Figura 3. - Estatua sedente del (abecico del Tesoro, Verdolay. Visia lateral.

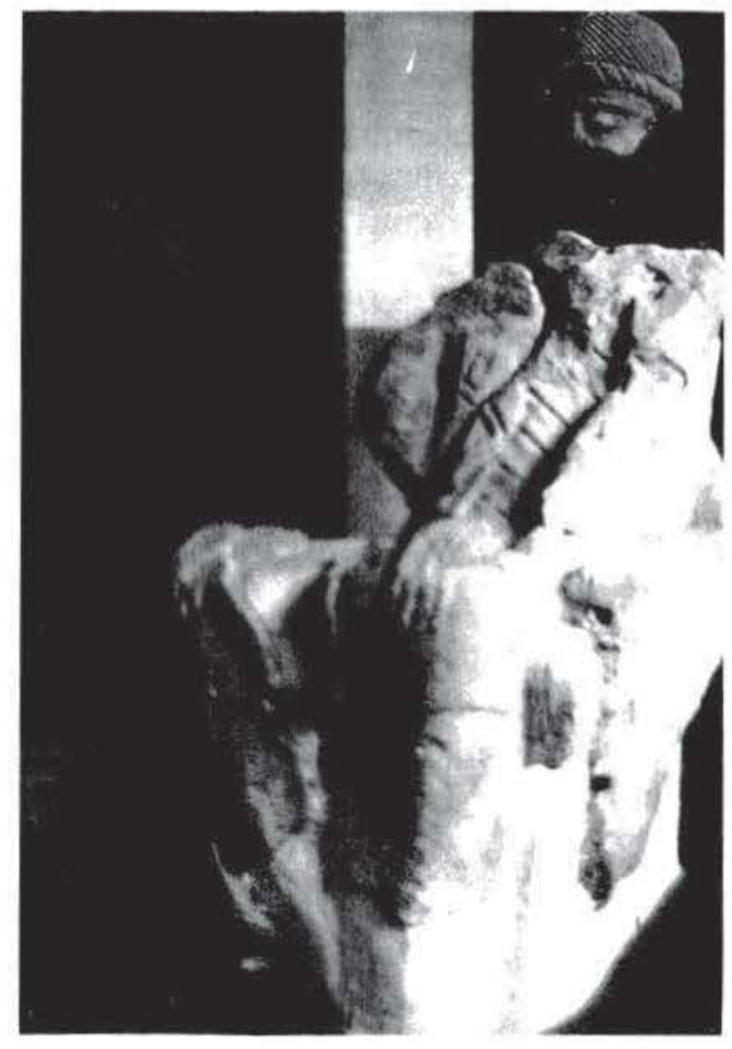

Figura 4. - Otra perspectiva de la estatua sedente del Cabecico del Tesoro. 
la búsqueda de paralelos formales y en el análisis del significado de la postura sedente. Sera destacado principalmente su carácter funerario, por el contexto en el que aparece y también por la confirmación que en este sentido proporcionan nuevos hallazgos, algunos tan espectaculares como el de la Dama de Baza ${ }^{20}$. En el ámbito de la investigación sobre la religiosidad ibérica tiene especial importancia la identificación de ésta y otras estatuas de parecidas características con representaciones de divinidades ibéricas. Tal es el caso de A. Blanco ${ }^{21}, \mathrm{~J}$. M. Blázquez ${ }^{22}$, y otros, que creen posible reconocer, entre las damas sedentes del Sudeste peninsular, la imagen de una "Diosa Tierra», señora del mundo de la Fecundidad y también del de la Muerte.

Termina este recorrido por la bibliografía que ha merecido la estatua de Verdolay con los trabajos de E. Ruano. En el primero de ellos y tomando como fundamento «la singularidad del trono o sillón, el atuendo y el tocado, humanizado en la iconografía", así como por el hallazgo de todas las estatuas de damas sedentes ibéricas en lugares destruidos, ya sean necrópolis, ya santuarios, la autora apunta la posibilidad de que todas ellas sean representaciones de diosas ${ }^{23}$. Con más extensión es estudiada la figura de Verdolay, años más tarde, por la propia E. Ruano ${ }^{24}$. Si bien ahora la estatua sigue siendo catalogada y contabilizada a todos los efectos como imagen femenina ${ }^{25}$, en algún momento se duda de este carácter ${ }^{26}$, aparentemente por plantearse la autora el dilema entre seguir el criterio de G. Nieto sobre la unidad de los dos fragmentos ${ }^{27} \mathrm{y}$, al mismo tiempo, admitir las conclusiones de W. Trillmich acerca del tipo masculino del peinado representado en la cabeza. Para E. Ruano las explicaciones a este problema se cifran en las siguientes: o bien «se trata de una excepción iconográfica, es decir, es un personaje masculino", o bien la cabeza no pertenece al cuerpo o, por último, «se representó (...) una imagen femenina tomando como prototipo una figura masculina" ${ }^{28}$.

En los estudios hasta ahora citados se echa de menos una análisis más pormenorizado de la figura y, especialmente, de su atuendo, circunstancia ésta que sorprende, cuando nos encontramos con que éste no sólo es susceptible de ser analizado sino también de documentar detalladamente dentro de la plástica ibérica.

Llegados a este punto es de justicia recordar las palabras con las que A. Garcia y Bellido describia, en 1943, la estatua de Verdolay:

"Un personaje, de tamaño algo menor que el natural, probablemente masculino, se halla sentado en un a modo de sillón de alto respaldo y base maciza, con una rigidez y envaramiento grande, que se acentúa por la simétrica disposición de los brazos, que van rectos a descansar (mejor a presionar) sobre las rodillas. Toda la figura se ve envuelta por una amplia vestidura, difícilmente comprensible, pero cuyos pliegues rectos y paralelos acusan un estadio primitivo sin duda influido por el arcaísmo griego".

\footnotetext{
${ }^{20}$ F. Presedo, La Dama de Baza, TP, 1973, 151-216.

${ }^{21}$ Historia de Arte Hispánico I. La Antigüedad, 2, Madrid, 1981, p. 49.

22 Religiones Primitivas de Hispania II: Primitivas Religiones Ibéricas, Madrid, 1983, p. 180-1.

2.3 "Esculturas sedentes en el mundo ibérico", Boletín de la Asociación Española de Amigos de la Arqueologia, 19, junio, 1984, 23-31.

${ }_{24}$ La escultura humana de piedra en el mundo ibérico, Madrid, 1987.

25 Ibid., vol. III, p. 52-3; vol. I, p. 261-298 y cuadro núm. 9.

26 Ibid., vol. II, p. 198-9.

27 Ibid., vol. III, p. 54 y 56.

28 Ibid., vol. II, p. 16.
} 
A lo largo de las próximas páginas me propongo estudiar de nuevo este importante testimonio de la escultura mayor ibérica, tomando el citado texto de A. Garcia y Bellido como hilo conductor. La "amplia vestidura» en la que "se ve envuelta" la figura y que en aquellos momentos resultaba al gran investigador de la arqueología ibérica «difícilmente comprensible», será el principal elemento a tener en cuenta.

La estatua no se halla, efectivamente, tan deteriorada como para impedir su estudio, ni hasta el punto que no permita reconocer las claves de su atuendo tras una observación detenida y directa. Pero antes de centrarnos en este aspecto, conviene recordar que la figura entra, sin dificultad, en lo que podría considerarse la categoría «monumental» de la plástica ibérica, no sólo por su empaque sino también por sus dimensiones reales. Sus medidas actuales son $67 \mathrm{~cm}$. de altura, $61 \mathrm{~cm}$. de profundidad y $47 \mathrm{~cm}$. de anchura. El trono se conserva hasta una altura, en el respaldo, de $57 \mathrm{~cm}$., lo que da una idea del nivel que alcanzaba con respecto al personaje sentado.

Un aspecto que llama la atención en este primer acercamiento a sus proporciones es la gran profundidad del asiento en relación al tamaño de la figura, algo poco habitual en otras manifestaciones ibéricas del tipo sedente. Si unimos a esto la buena interpretación del ángulo recto que forman el tronco y las extremidades inferiores en virtud de la postura y que resulta el principal escollo en la elaboración de este tipo escultórico ${ }^{29}$, tendremos que admitir que nos encontramos ante una obra de cierta categoría y ante un escultor diestro en su oficio, lo que no puede ocultarse a pesar del grado de deterioro de la estatua.

Este último aspecto es ciertamente de lamentar ${ }^{30}$ : de los pies y parte baja del trono se ha perdido todo, arrancando lo conservado desde algo más arriba de los tobillos. También se ha perdido la mayor parte del lateral derecho de la figura (si exceptuamos la rodilla, sobre la que se apoya la mano correspondiente) y el brazo derecho del sillón. Un trozo muy deteriorado del brazo nos permite anotar, al menos, que éste se encontraba algo más adelantado que el izquierdo; en éste y otros detalles la figura no se mostrará estrictamente simétrica.

Continuando con las partes perdidas lo más penoso es, sin duda, la ausencia de la parte superior del pecho, con los hombros y cuello, amén de la cabeza. El frente y el lateral izquierdo se hallan mejor conservados, lo suficiente para reconstruir hipotéticamente lo perdido (fig. 2).

La imagen representada en el Cabecico del Tesoro viste una túnica ${ }^{31}$ cuyos únicos vestigios se limitan hoy a la manga corta que deja al descubierto el brazo izquierdo y tres pequeños pliegues casi paralelos que confluyen bajo la axila izquierda. La prenda que se superpone

${ }^{29}$ Cifr.: W. Fuchs, Die Skulptur der Griechen, Munich, 1979.

${ }^{30}$ Vid.: F. Quesada, "Sobre la cronologia de la destrucción escultórica en la necrópolis de "El Cabecico del Tesoro" (Verdolay, Murcia)", Boletín de la Asociación Española de Amigos de la Arqueología, 26, 1989, 19-24; Op. cit. en nota 2, I p. 116-126 para el estado de la fragmentación y destrozo de ésta y las restantes necrópolis del yacimiento.

${ }^{31}$ En pintura cerámica la inmensa mayoria de estas túnicas tiene, además, escote en ángulo: Corpus Vasorum Hispanorum: Cerámica del Cerro de San Miguel de Liria, 1954, figuras 396, 462, 485, $510,517 \ldots$ En el Cerro de los Santos hay variedad entre los escotes redondeados de la figura número 40, el excepcional escote tipo «barco» (núm. 229) y los escotes en ángulo (núm. 135), algunos con una tira bordeándolo (núm. 159) (M. Ruiz Bremón, Los exvotos de Santuario ibérico del Cerro de los Santos, Albacete, $1989 M R B$, p. 121). En otras figuras de piedra es también habitual la variedad de unos y otros (E. Ruano, Op. cit. en nota 24, vol. I, cuadros 20-24, 38-41). Entre los bronces, en cambio, sólo se da el escote en pico, siendo el recto excepcional (G. Nicolini, Les bronzes figurés des Sanctuaires ibériques, Paris, 1969, p. 149, nota 1). 
a la citada túnica es amplia y larga, si hemos de juzgar por la abundancia de pliegues representados y por la longitud que alcanza en la parte baja de la estatua. Estos pliegues son rectos y paralelos en el costado izquierdo y parte del frente, atravesando oblicuamente el pecho desde su lugar de origen, en la cadera, hasta su punto final en el hombro derecho.

A mitad de su camino, sin embargo, quedan ocultos bajo otro grupo de pliegues, éstos con una configuración distinta: son pequeños pliegues de caída convencional, zigzagueante, esto es, de los llamados «arcaicos» o «arcaizantes» por su vinculación a la estética griega de este nombre, aunque no necesariamente de este periodo ${ }^{32}$.

Tanto estos pliegues como los anteriores se explican por el modo de disponerse el manto sobre el personaje: la prenda, rectangular, ha sido doblada, previa su colocación, en dos o tres tercios de su altura ${ }^{33}$, motivo por el cual va a presentar un típico doblez ${ }^{34}$ horizontal aproximadamente a la altura de las espinillas. Una vez terciado, el manto se hace pasar bajo uno de los brazos, aquí el izquierdo ${ }^{35}$, desde donde una mitad del paño atravesará el torso «subiendo» hasta el hombro contrario y la otra mitad hará lo mismo a través de la espalda para unirse alli con el anterior mediante una fíbula u otro sistema de fijación ${ }^{36}$. El sobrante del paño delantero en su unión con el posterior sobre el hombro izquierdo conforma, en la figura de Verdolay, el grupo de pliegues zigzagueantes sobre el pecho ${ }^{37}$, aunque también po-

${ }^{32}$ Ya en 1954 A. García y Bellido se muestra contradictorio y dubitativo sobre esta cuestión en lo relativo a la figura del Verdolay (Op. cit., en nota 11, p. 504 y 6). Entre los muchos ejemplos aducibles valga el exvoto masculino del Cerro de los Santos del Museo Provincial de Albacete (MRB, núm. 159).

${ }^{33}$ Entre los numerosos ejemplos que pueden ser recordados, algunos de los mejor conocidos son el bronce "Vives» (F. Álvarez Ossorio, Catálogo de los exvotos de bronce ibéricos, Madrid, 1941, núm. 1653) y la figura hallada por G. Nieto casualmente en el Cerro de los Santos en 1960 (A. Fernández Avilés, "Zwei Skulpturen von Cerro de los Santos in Orihuela», MM, 7; Id. "Cerro de los Santos, Montealegre del Castillo (Albacete), Primera Campaña», 55, 1966, p. 21; A. Garcia y Bellido, op. cit. en nota 16, p. 37, figs. 33-34. M. Ruiz Bremón: «Piezas inéditas del Cerro de los Santos en la Casa de la Cultura de Yecla», Al-Basit, 15, 1984, 15-30; Id.; Op.cit. nota 31, fig. 157).

34 En los bronces, este doblez es de dos tercios o de tres cuartos de la altura total del manto (G. Nicolini, op. cit. en nota 31, fig. 157). V.gr.: MRB, núm. 139, en el Museo Provincial de Albacete.

${ }^{35}$ En el Cerro de los Santos se puede hallar indistintamente prendido sobre el hombro derecho o izquierdo. Esto no varía, sin embargo, por el modo de caer el manto a partir de aqui, dejando que baje vertical por el costado o recogiéndolo la mano izquierda, puesto que tenemos ejemplos en los que se hallan mezclados uno y otro sistema. (M. Ruiz Bremón, op. cit. en nota 31, p. 121-2.) Debo corregir aqui mi afirmación de que en el Cerro de los Santos los mantos no caen rectos por el costado (p. 121). La figura número 174 parece responder a lo contrario, dejando la pierna derecha al descubierto. Tenemos otros ejemplos en el Cipo de Jumilla (A. M. Muñoz «Cipo funerario ibérico decorado con esculturas", XVI C.N.A. Murcia-Cartagena, 1982-3, Murcia, 1983, 741-748); en el Relieve de la Albufereta (J. Lafuente Ferrari «Un alto relieve en la necrópolis cartaginense de la Albufereta», Las Ciencias, 1935, 878-8) y en el 'Otorso de Elche (A. Ramos Folques "Hallazgos escultóricos de la Alcudia», A.E.A., $23,1950,353-359$, fig. 8).

${ }^{36}$ En el Cerro, de donde proceden la mayoría de las estatuas de varón de la plástica ibérica, son más abundantes las anulares (núms. 133, 134, 140, 160, 368, 372) aunque también se encuentran pasadores en «T» (núms. 148 y 165). (M. Ruiz Bremón, op. cit. en nota 31, p. 124-126.)

${ }^{37}$ Los ejemplos en el arte ibérico de la utilización de la convención arcaica para simular la caída de los paños, son muy abundantes. Baste recordar a las Damas de Elche o Baza, la figura sedente de la Alcudia de Elche (A. Ramos Folques, op. cit. en nota 35, p. 353, fig. 6), el Gran Sacerdote de Cerrillo Blanco (J. A. González Navarrete, Escultura ibérica de Cerrillo Blanco, Porcuna, Jaén. Jaén, 1987, núm. 15, pp. 103-6), y numerosas figuras masculinas y femeninas del Cerro de los Santos, entre las que se incluyen representaciones de pliegues arcaicos (M. Ruiz Bremón, op. cit. en nota 31, figs. 5 y 
dria tratarse del borde longitudinal del manto, al que se dota asi de un recurso ornamental ${ }^{3 *}$ (fig. 6).

Unos centímetros más abajo de la bocamanga izquierda, la figura exhibe un sencillo brazalete de sección cuadrangular, muy deteriorado y sólo visible desde el lateral izquierdo, aún con dificultad ${ }^{34}$.

Cabe la duda de que la mano se adorne con un anillo, por lo deteriorado de su superficie y por su extraña ubicación, al final de la segunda falange del dedo anular ${ }^{41}$.

Lo mismo cabe decir acerca de las posibles pulseras, al haberse perdido ambas muñecas y el regazo del personaje.

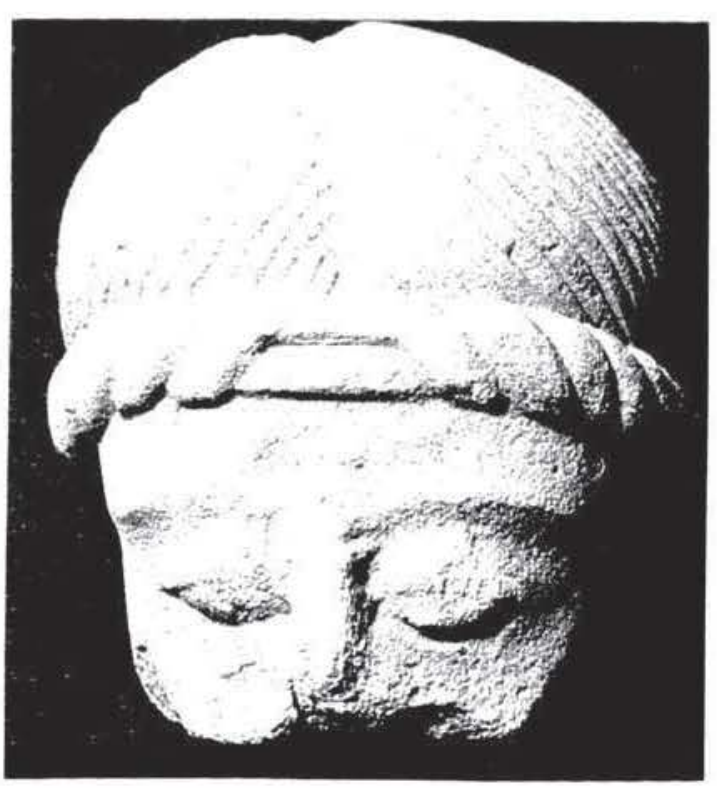

Figura 5.-Cabeza masculina en piedra. Cabecico del Tesoro de Verdolay. Museo Arqueológico de Murcia.

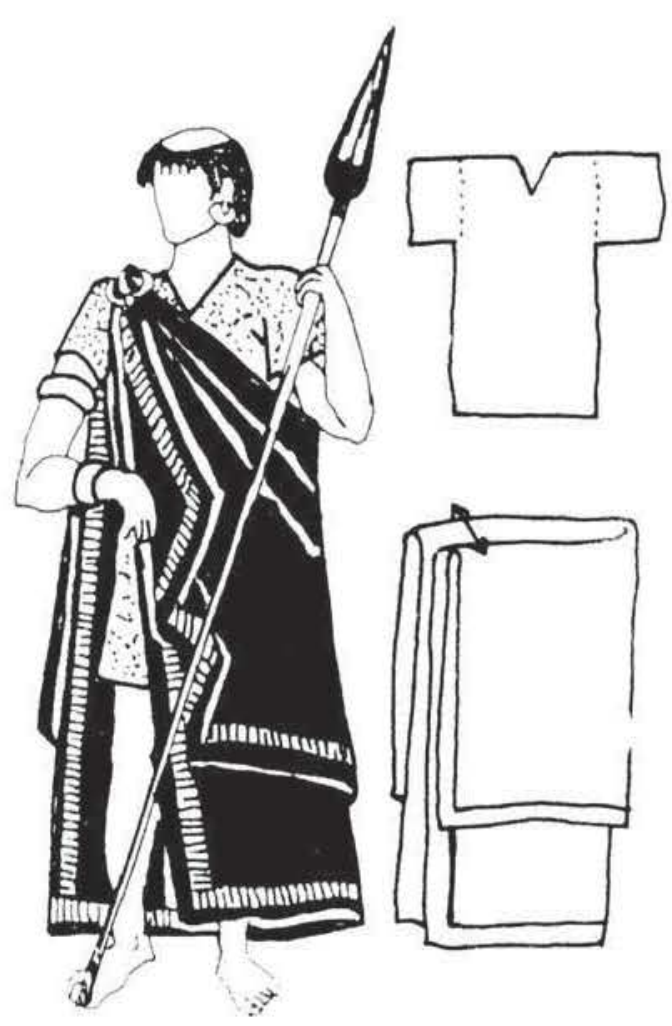

Figura 6.-Atuendo varonil ibérico, según E. L.lobregat (1972).

174), y pseudoarcaicos (Ibid., figs. 53, 62, 108, 110, 115, 157, 159). Tampoco faltan entre los bronces: AO 1739, pero en una imagen femenina, según Nicolini, influida por las del Cerro de los Santos (op. cil. en nota 31 , pág. 207 , nota 2 , fig. 10 ).

${ }^{36}$ E. Llobregat, Contestania Iberica, Alicante, 1972, fig. 117.

${ }^{39} \mathrm{Vid}$., ejemplos de uno, dos o más brazaletes y pulseras en estatuas de varones en piedra en: M. Ruiz Bremón, op. cit. en nota 31, pp. 140-1, núms. 419, 141, 148, 162-4, 167-8, 209, 172, 215, 425-7..; E. Ruano, op. cit. en nota 24, vol. 1, cuadros 21-23, 25, 39 y 40. Para los bronces: G. Nicolini, $o p$. cit. en nota 31, pp. 229 y 234 . En pintura cerámica: el gran vaso de los guerreros de Liria (op. cit. en nota 31, pág. 60-61, lám. LXV, fig. 45), y el de la Serreta de Alcoy (A. Garcia y Bellido, op. cit. en nota 11 , fig. 605 ).

${ }^{40}$ Si llevan anillos algunas figuras del Cerro de los Santos. (M. Ruiz Bremón, op. cit. en nota 31 . núms. $215,427,429,437 \ldots)$. 
Poco se puede añadir, por último, a la descripción del trono apuntada, en su dia, por A. García y Bellido, que destacó en él su «alto respaldo y base maciza». Su mal estado de conservación no nos permite siquiera imaginar el modo de rematar el respaldo ${ }^{41}$ ni los brazos, aunque el primero sería curvo; ni la forma de las patas del asiento, si es que estaban representadas. Sí destaca en cambio en el trono una cierta asimetria, no achacable al estado fragmentario en el que éste se encuentra. El brazo derecho resulta más bajo que el izquierdo, distinta su unión con la pata correspondiente y, sobre todo, más distanciado de la figura que en el lateral opuesto. El resultado: la apariencia de que el personaje se ha sentado ligeramente desplazado hacia la izquierda y no exactamente en el centro del trono ${ }^{42}$.

El atuendo generalizado entre los varones ibéricos es hoy tan bien conocido como el de las damas ${ }^{43}$, de ahí que me atreva a afirmar que el representado en la figura sedente de Verdolay es de tipo masculino.

Los ejemplos aducidos hasta el momento en escultura en piedra pueden ser ampliados con los de los bronces y pintura vascular ${ }^{44}$, con lo que tendríamos un repertorio de paralelos formales internos bastante extenso, tanto geográfica como temporalmente hablando ${ }^{45}$.

La iconografía de los varones en la plástica ibérica se completa con uno o dos pendientes ${ }^{46}$ como adorno. Varía en gran manera, sin embargo, el tipo de peinado y tocado según las épocas y regiones, pero esto, obviamente, no viene al caso en un estudio dedicado, como éste, a una figura hoy considerada acéfala.

El calzado, cuando se refleja, puede ser abierto o cerrado, incluyendo dentro de esta categoría las botas ${ }^{47}$. En algunas ocasiones asoma bajo unas "polainas» ${ }^{48}$, como podría ser el

${ }^{41}$ En efecto, podría haber sido más ancho a partir de la mitad de su altura, como el trono de la Dama de Baza (F. Presedo, op. cit. en nota 20), o el de una figurilla de terracota de Boston de finales del periodo arcaico (G.M.A. Richter, The Furniture of the Greeks. Etruscans and Romans, Londres, 1966, fig. 98).

${ }^{42}$ Ignoro cómo interpretar el orificio que se observa en el lado izquierdo del trono. ¿Sirvió para sujetar el vástago de una pieza más sobresaliente, o para recomponer una rotura antigua? En las primeras fotos de la figura, una vez limpia y restaurada, ya aparece (G. Nieto, op. cit. en nota 2, figs. XI y XII).

${ }^{43}$ M. L. Bandera, «El atuendo femenino ibérico», Habis 8, 1977, pp. 253-297; 9, 1978, págs. 401440; M. Prada, «El vestido y los adornos en el mundo ibérico. La indumentaria en los exvotos ibéricos de El Cigarralejo", Boletín de la Asociación Española de Amigos de la Arqueologia, 11-12, 1979, pp. 27 y ss.; 13, 1981, pp. 31-39.

${ }_{44}$ Sólo relativos a la túnica corta, ya que no se representan mantos: C.V.H., op. cit. en nota 31, núms. $486,487,491$, etc.

${ }^{45}$ La figura de Verdolay sería uno de los ejemplares más antiguos, junto con el Cipo de Coimbra del Barranco Ancho (Op. cit. en nota 35). Más tarde se fecharían, entre otros, el ejemplar de la Albufereta (op. cit. en nota 35$)$ y el bronce «Vives» (op. cit. en nota 33).

46 Vid. J. Cabré, «Guerreros indigenas de la Edad del Hierro en la Península Ibérica, con pendientes de oro", Las Ciencias, 2, 1934, pp. 132-5; A. Muñoz Amilibia, op. cit. en nota 35; J. Lafuente, op. cit. en nota 35; E. Ruano, op. cit. en nota 24, cuadros 20, 25, 26-37. En las imágenes del Cerro de San Miguel de Liria, no resultan, a mi entender, del todo claros. En los bronces también tenemos algunos ejemplos: G. Nicolini, op. cit. en nota 31, PI. XI, 5-7, y PL. XVII, 1-4.

${ }^{47}$ En escultura en piedra tenemos ejemplares del Cerro de los Santos (M. Ruiz Bremón, op. cit. en nota 31, pp. 127-8) y otros testimonios (E. Ruano, op. cit. en nota 24, T. I, p. 483, nota 23 y cuadros 42-44). En pintura vascular se representan con toda claridad las botas (Op. cit. en nota 31, pp. 113-114, núms. 482-3, 498, 501-2, 506...).

48 En el Cerro de los Santos sólo en un caso: la figura núm. 174 (M. Ruiz Bremón: op. cit. en nota 31, pp. 127-8), hallada por A. Fernández de Avilés en 1962 (op. cit. en nota 33, núm. 38). Las piezas 
caso que nos ocupa, si no es porque a menudo la parte inferior de las estatuas de piedra presenta un acabado muy somero, sin delimitar correctamente. Y si bien es verdad que en la iconografía de la mujer ibérica hallamos también mantos prendidos al hombro - comenzando por la Dama de Elche y siguiendo por los bronces - también lo es que en ningún caso dejan de estar asociados a velos que cubren los hombros, si no toda la fig ura, como en el caso del exvoto del Museo Arqueológico Nacional catalogado por F. Álvarez Ossorio con el núm. 2323, entre otros muchos ejemplos.

Ninguna imagen femenina se presenta, por lo conocido, exenta de un velo o de un manto que cubra sus hombros. Las mujeres con túnica ceñida como única pieza de su atuendo deben ser equiparables a los varones con túnica corta y no al tipo aquí estudiado.

La mayoría de los ejemplos propuestos pueden considerarse petenecientes a un tipo de atuendo "pacífico", que no es otro que el que tiene como base la túnica corta y ceñida de algunos bronces y de la pintura vascular ${ }^{49}, \mathrm{y}$ al que se añade el manto en señal de respeto cuando las imágenes tienen carácter votivo o funerario. En otras palabras, en aquellos contextos en los que se quiera o deba marcar el sentido de respeto ante la divinidad, aunque no necesariamente en los que reine la estabilidad y la paz: los bronces armados, que se mezclan con los exvotos "pacíficos" en los Santuarios ibéricos, indican lo contrario ${ }^{50}$.

La postura sedente es conocida en la plástica mayor ibérica ${ }^{51}$ así como en la pintura ${ }^{52}$, pero salvo excepciones muy singulares, como el fragmento de Kalathos del Castellito de Alloza en Teruel ${ }^{53}$ (fig. 7), en el que un hombre sentado sobre silla de alto respaldo es considerado por L. Pericot un pastor de ganado, o poco representativas de lo más genuinamente ibérico, como Tivissa y Pozo Moro ${ }^{54}$, se trata de imágenes femeninas. Hoy podrían añadirse al catálogo de damas sedentes que elaboró E. Ruano en 1989, los ejemplares de Cerrillo Blanco (Porcuna, Jaén) ${ }^{55}$, Torreparedones (Castro del Río, Baena, Córdoba) ${ }^{56}$, y Alcoy ${ }^{57}$

núms. 227 y 228 están asociadas a un "pallium» romano y por tanto no pueden considerarse el mismo elemento.

${ }^{49}$ En los vasos de Alcoy y Oliva (L. Pericot, La cerámica ibérica, Barcelona, 1979, figs. 176-81 y 169-75), San Miguel de Liria (Op. cit. en nota 31, pp. 113-114) y en los bronces votivos en general (G. Nicolini, op. cit. en nota 31, pp. 148-155).

${ }^{50}$ M. Ruiz Bremón, «Retratos y categorías sociales en el Cerro de los Santos», Actas del l Congreso Peninsular de Historia Antigua, Santiago, 1986, Santiago de Compostela, 1988, 119-133.

${ }^{51}$ E. Ruano, Op. cit. en nota 23, p. 23, recoge los siguientes testimonios: Villaricos, Galera, Baza, Cerro de los Santos, Llano, Vizcarra, La Alcudia y Cabecico. En 1987 (Op. cit. en nota 24, vol. 1, pp. 261 y ss.) añade tres ejemplares más: dos de Fuerte del Rey (Jaén) y uno de Cádiz.

52 En San Miguel de Liria (Op. cit. en nota 31, pp. 115, 527, fig. 69 y pp. 112, 472, fig. 82), Sta. Catalina del Monte (M. Jorge Aragoneses, «El vaso ibérico de Sta. Catalina del Monte (Murcia). A.E.A., 42, 1969, 200), La Serreta de Alcoy (V. Pascual, «Otros fragmentos con figuras humanas», Serie de Trabajos Varios, II, 1947, pp. 62-63) y otros ejemplos en pintura vascular, aunque los hay también de pintura sobre cistas de piedra (A. Garcia Bellido, op. cit. en nota 11, pp. 602, 603, fig. 529; J. CabréF. Motos, "La necrópolis ibérica de Tutugi (Galera, Granada)», M.S.E.A., 25, 1920, pp. 69 y ss.; J. M. Blázquez, "La urna de Galera», Caesaraugusta, 7-8, 1956, pp. 99 y ss.).

53 L. Pericot, op. cit. en nota 49, fig. 418, p. 259.

54 J. M. Blázquez, Imagen y Mito, Madrid, 1977, pp. 221-245; M. Almagro Gorbea, «Los relieves orientalistas de Pozo Moro (Albacete, España)», T.P., 35, 1978, pp. 251-278.

s5 J. A. González Navarrete: op. cit. en nota 37, núm. 37, pp. 269-7.

56 J. A. Morena López, El Santuario ibérico de Torreparedones. Castro del Rio, Baena, Córdoba, Córdoba, .1989, pp. 61-62, fig. 2, lám. LXV, LV, B.

${ }^{57}$ E. Cortell, J. Juan, J. M. Segura y J. Trelis: «Dos nuevas esculturas ibéricas en la Contestania: 
y la aún inédita del Cigarralejo (Mula, Murcia). Por el contrario, quizá fuera aconsejable excluir del mismo a la Dama de Galera ${ }^{58}$, por corresponder a un contexto cultural y cronológico bien distinto al de las restantes.

Pero si el tipo sedente femenino, aún sin ser mayoritario, se encuentra extendido por todo el ámbito ibérico y todas sus épocas, no ocurre lo mismo, hasta el momento, con el tipo masculino. Los paralelos iconográficos a la figura del varón sentado de Verdolay deberán buscarse, por tanto, en ambientes culturales extrapeninsulares y en concreto en el mundo griego, de donde no sólo parece que es tomada la idea, sino también algunos de sus rasgos formales.

W. Trillmich apuntó en 1975 como un error el considerar paralelos directos de esta pieza a las estatuas sedentes del primer arcaísmo jónico ${ }^{59}$, siendo más próximos en el tiempo y en el espacio los que proporcionan Magna Grecia y Sicilia durante el bajo arcaismo y el periodo severo. Si nos atenemos a lo dicho sobre el sexo de la figura, tendríamos que actualizar esta cuestión recurriendo de nuevo a las estatuas de los Bránquidas y a otros ejemplos de figuras sedentes masculinas que se crean durante época arcaica alta ${ }^{60}$ y que persisten como tipo escultórico con finalidad funeraria y votiva, aunque siempre de un modo minoritario, a finales del arcaísmo ${ }^{61}$. No por ello han de excluirse los modelos femeninos, particularmente en lo relativo a la postura de las manos, que "van rectas a presionar (...) sobre las rodillas» ${ }^{62}$, y al tipo de trono. Este, como ya se indicó, tiene asiento macizo y respaldo recto, sin que pueda aventurarse más sobre él y sus paralelos ${ }^{63}$, so riesgo de caer en el terreno de la pura hipótesis.

Pero estos modelos son estrictamente formales, y a ellos podrian añadirse otros muchos haciendo esta relación, si no interminable, sí mucho más extensa. Quizá más importante, a mi entender, resultaría el analizar el "porqué» y el "para qué» se toma prestada una idea, la del varón sentado, más que la manera de representarla. Esta, como hemos podido comprobar, es susceptible de adaptación a un lenguaje iconográfico propio, reflejando por ejemplo, un atuendo «nacional». En el mundo griego, la idea del varón sedente parece surgir como respuesta a una necesidad funerario-votiva ${ }^{64}$, y desarrollarse en un primer momento parale-

toro y dama de Benimassot", XIX Congreso Nacional de Arqueología, Castellón de la Plana, 1987 (en prensa).

58 J. Cabré, F. Motos: op. cit. en nota 52; P. J. Riis: "La estatuilla de alabastro de Galera", C.H.P., 1950, pp. 113-121.

59 W. Trillmich, op. cit. en nota 17, p. 213 , nota 17.

60 Junto a la serie de los Bránquidas (K. Tuchelt, «Die archaischen Skulpturen von Didyma», Istambuler Forschungen, 27, 1970) hay que recordar la masculina de Magoula, Esparta (P. Kranz, «Frühe griechische Sitzfiguren - Zum Problem der Typenbildung und des orientalischen Einflusses in der frühen griechischekunst", Ath. Mitt., 87, 1972, pp. 1-55); y la discutida de Aiakes (B. Freyer-Schauenburg: «Bildwerke der archaischen Zeit und des strengen Stils», Samos, XI, Boston 1974, núm. 67).

61 La más paradigmática sería la del llamado Dionysos, hoy considerada una imagen funeraria, así como la también masculina del Cerámico (J. Boardman-D. Kurtz: Greek burial customs, LondonSouthampton, 1971, p. 89). Carácter votivo tendrían, en cambio, los llamados «escribas» de la Acrópolis (H. Payne-G. Mackworth Young: Archaic Marble Sculpture from the Acropolis, Londres 1950, pl. 118, pp. 46-7).

62 Vid. B. S. Ridgway: The Archaic Style in Greek Sculpture, Princeton, 1977, pp. 122-139, para la bibliografía de los ejemplares de Gortina y Prinias, Arcadia, Paros y Delos, Magna Grecia y Atica durante el período arcaico. También es tratado con extensión este tipo por W. Fuchs, op. cit. en nota 29, pp. 254-9.

${ }^{63}$ G. M. A. Richter, op. cit. en nota 41 , pp. 28-33, figs. 123-25.

64 Esta idea ya fue apuntada por M. Collignon (Les statues funéraires dans l'art grec, París, 1911, pp. 65 y ss.) y seguida por B. S. Ridgway (op. cit. en nota 62, p. 143). 
lamente al tipo sedente femenino ${ }^{65}$. También se empleará para las estatuas de culto, aunque dados los pocos testimonios de este rango y los abundantes ejemplos de diosas sentadas aparecidas en contextos votivos y funerarios del Occidente griego, se tiende a alinear entre las femeninas a aquellos testimonios mal definidos o mal conservados en los que no esté clara la cuestión del sexo. Pero a partir del periodo arcaico va prácticamente a desaparecer de las representaciones en bulto redondo, lo que no ocurre con el tipo femenino, asociado unas veces e interpretado otras, con Demeter-Perséfone, Hera, Afrodita, Atenea u otras divinidades de carácter funerario. Este tipo, por lo demás, va a tener un especial arraigo entre los griegos occidentales, esto es, en Sicilia y Magna Grecia ${ }^{66}$. El primitivo carácter de retrato o imagen del difunto inherente a aquellas manifestaciones escultóricas fúnebres, se verá así sustituido por el de la imagen de la divinidad, votiva y propiciatoria.

Sin embargo, en el Cabecico del Tesoro estamos ante una necrópolis en una de cuyas tumbas se situó un dia, seguramente al aire libre, la estatua de un hombre sentado (siempre juzgando por su atuendo). Es más probable que tal imagen perteneciera a un varón de alto rango que a una estatua divina. Tendriamos así un testimonio más de la asimilación de la idea griega de la heroización por parte del mundo ibérico.

Es innecesario insistir en la importancia de este supuesto que, de confirmarse, indicaría la conservación de una misma idea en la Grecia continental y en un área sometida a su influencia, si bien allí el modo de expresión habría cambiado radicalmente desde los tiempos del arcaísmo y aqui, por el contrario, se conservarian sus rasgos iniciales: la imagen en bulto redondo y no en relieve; la postura rígida y no naturalista; la posición simétrica de las manos sobre las rodillas, etc. ${ }^{67}$. En apoyo de esta idea están su atuendo, propio de los varones ibéricos, y el hecho de que nada lo diferencie de otras manifestaciones de éstos en piedra, bronce o pintura. Por mi parte he defendido el carácter humano de las representaciones femeninas sedentes del Santuario del Cerro de los Santos, por carecer, como ésta, de todo rasgo diferenciador, litúrgico o iconográfico, con respecto a los demás exvotos ${ }^{68}$. La ausencia por el momento de imágenes divinas en la plástica ibérica, aunque pueda ser un argumento sólo coyuntural, como indicaría el hallazgo de un fragmento de cabeza, masculina, en el templo "A»" de Campelló ${ }^{69}$, también avala, hoy por hoy, tal hipótesis. Si hay razones para considerar a

65 B. S. Ridgway, op. cit. en nota 62 , pp. 121-147. En efecto, ya entre los Bránquidas hay hombres y mujeres y en Grecia Central tenemos tanto imágenes femeninas (Agiorgitika, Agemo) como masculinas (Esparta) en el alto arcaismo.

${ }^{66}$ Para los numerosos ejemplos de estatuas sedentes femeninas durante el periodo arcaico, severo y clásico en terracota en esta zona, Vid.: E. Langlotz-M. Hirmer: The art of Magna Grecia, Londres 1965; R. A. Higgins: Greek Terracottas, Londres 1967; E. Gabrici: Il Santuario della Malophoros a Selinunte. Monumenti Antichi XXXII, pp. 192; B. Pace: Arte e civiltà della Sicilia Antica VI: Arte. Ingenieria e Artigianato, Milán, 1938. Para aspectos relativos a los cultos: G. Gianelli, Culti e miti della Magna Grecia, Florencia 1963; T. Hadzisteliou Price, Kourotrophos, Leiden 1978; y G. Zuntz, Persephone, Oxford, 1971. Sobre la diosa de Tarento, en piedra; B. S. Ridgway, The severe style in Greek Sculpture, pp. 93-94. C. Blümel, Die klassisch griechischen Skulpturen der Staatlichen Museen zu Berlin, Berlin 1966; H. Herdejürgen, Die thronende Göttin aus Tarent in Berlin, Waldsassen, 1968.

${ }^{67}$ Los precedentes arcaicos de las estelas áticas y su relación con la idea de la heroización son estudiados por K. F. Johansen, The Attic Grave-Reliefs of the Classical Period, Copenhague, 1951; y G. M. Richter, Archaic Gravestones of Attica, Londres, 1961.

${ }^{68}$ M. Ruiz Bremón, op. cit. en nota 50.

${ }^{69}$ E. Llobregat, «El conjunto de templos ibéricos de la "Illeta d'els Banyets" (El Campelló)», Studia Historica in honorem Vicente Martínez Morellá, Alicante, 1985, pp. 186-205. 
la figura de Verdolay como una imagen funeraria, no las hay, en cambio, para creerla una imagen divina.

Queda por último, la cuestión de la cronología. Para resolverlo contamos, de una parte, con el estudio de los datos proporcionados por la propia necrópolis, recientemente ampliados por F. Quesada ${ }^{70}$, y con al análisis de la propia estatua. Sabido es que la escultura ibérica no nos permite todavia hoy más que someros acercamientos al problema de la cronologia cuando faltan los datos arqueológicos objetivos. De ahí que haya que seguir recurriendo el análisis comparativo externo. Este permite situar los modelos originarios de la figura en el arte griego de finales del arcaísmo y primera mitad del siglo $\mathrm{V}$ a.C., y se refieren tanto a la propia postura sedente como al tipo de trono y la posición de las manos. Incluso cabría considerar como tales el modo de disponer e interpretar el plegado de los paños que se da en estatuas en piedra de la misma época ${ }^{71}$. Ahora bien, como ya se planteó en relación a la cabeza antes ligada a esta figura ${ }^{72}$, los modelos no tienen por qué ser contemporáneos de las obras que dependen de ellos, de los que incluso pueden estar muy distanciados en el tiempo. De ahí que resulten de un gran valor las últimas conclusiones de tipo cronológico sobre la escultura del Cabecico del Tesoro a las que llega indirectamente F. Quesada en su estudio de las armas de esta necrópolis. Hasta entonces, el único intento de datación de las destrucciones que acabaron con las esculturas de este yacimiento, aparecidas en un estado general de fragmentación y destrozo, se debía a G. Nieto, quien apuntó como hipótesis la fecha de la conquista Bárquida de la Península Ibérica en 237 a.C. ${ }^{73}$. Pero la datación por parte de Quesada de una parte de las tumbas con escultura en el siglo IV a.C., indica que al menos algunas fueron esculpidas a finales del siglo $v$ o primer cuarto del siglo $I V^{74}$, y que la necrópolis del Cabecico del Tesoro sufrió, como tantas otras ibéricas, una sañuda destrucción de sus monumentos funerarios en los albores del siglo IV a.C. ${ }^{75}$. O incluso antes, si quisiéramos acercarla más a sus paralelos formales del período severo. En la segunda mitad del siglo $\mathrm{v}$ la necrópolis tuvo que tener ya una cierta potencia, si consideramos que los fragmentos escultóricos aparecen no sólo reutilizados, sino también muy deteriorados y «rodados» en los primeros años del siglo IV $^{76}$.

${ }^{70} \mathrm{~F}$. Quesada, op. cit. en nota 2: «El armamento de la necrópolis ibérica de El Cabecico del Tesoro (Murcia)", C.P.A., 13-14, 1986-87, Homenaje al Profesor Gratiniano Nieto, II, 47-63.

${ }_{71}$ No puede evitarse aquí el recuerdo del Kuros núm. 633 del Museo de la Acrópolis $(H$. Schrader, E. Langlotz, W. H. Schuchhardt, Die archaischen Marmorbildwerke der Akropolis, Frankfurt, 1939, núm. 308 , pl. 128-9, figs. 202-3, pp. 204-7) por lo inhabitual en este momento de la figura masculina estante vestida.

${ }^{72}$ A. García Bellido, op. cit. en nota 8, p. 352; W. Trillmich, op. cit. en nota 17, p. 244.

73 G. Nieto: «La necrópolis hispánica del Cabecico del Tesoro, Verdolay (Murcia), Cuarta Compañía de excavaciones», BolSemEstudArteArq, 10, 1943-4, p. 173; op. cit. en nota 2, p. 183.

${ }^{74}$ F. Quesada, op. cit. en nota 2, pp. 116-126.

75 Los estudios sobre el tema de las destrucciones en necrópolis ibéricas son ya muy abundantes. Algunos en los que se recogen datos de carácter general o sobre los yacimientos más importantes son: M. Almagro, «Pozo Moro, un monumento funerario ibérico orientalizante», MM. 24, 1983, pp. 286 y ss.; «Paisaje y sociedad de las necrópolis ibéricas», XVI C.N.A. Murcia 1982, Murcia, 1983, pp. 400 y ss.; J. Aparicio, "La necrópolis de Corral de Saus y las evidencias de una primera revolución social», Papers de la Costera, 2, Játiva, 1982, pp. 42 y ss.; E. Cuadrado, «El problema de los restos escultóricos de las necrópolis ibéricas", Homenaje a don Antonio Beltrán, 1980, pp. 570 y ss.; González Navarrete, op. cit. en nota 37, p. 17; E. Ruano, «Primera gran destrucción escultórica en el mundo ibérico», Boletín de la Asociación Española de Amigos de la Arqueología, 23, 1987, pp. 58-62; J. Sánchez Jiménez, «Excavaciones y trabajos arqueológicos en la provincia de Albacete», Informes y Memorias, 15, 1942-46.

${ }^{76} \mathrm{~A}$ las mismas conclusiones, aunque basándose en aspectos estilísticos, llega E. Ruano, cuando 
Por último y aunque no es éste el objetivo de este estudio, queda por referirse al fragmento de cabeza antes asociado a nuestra figura, dado lo atractivo que resulta el volver a adscribir ambas piezas a una misma estatua, una vez supuesto el carácter masculino de las dos. En su dia, la proximidad de los fragmentos en torno a las tumbas números 114 y 119 , la semejanza de la piedra, de las proporciones y de la labra hicieron aconsejable su union. Menos probabilidades de pertenecer al cuerpo sedente parece ofrecer la cabeza hallada en $1955^{\circ}$ (figs, 8-9). Fue encontrada en otro área ${ }^{78}$ y sus proporciones son algo mayores que las de aquél. Queda, finalmente la opción de que la estatua haya perdido en el transcurso del tiempo y. junto con otras partes, su cabeza, y que debamos seguir resignándonos a considerarla acefala.

Ahora bien, seria sumamente interesante el análisis petrográfico tanto de los fragmentos que constituyen el cuerpo como de la cabeza. Con los datos proporcionados por dicho análisis quizá podrian descartarse uno o más de los supuestos citados, aclarando definitivamente esta cuestión y, quién sabe, si proporcionando también nueva información sobre la cantera originaria de la estatua, local o foránea.

Una vez más debo indicar que lo que me ha movido a este estudio no es tanto el tratar de averiguar qué tipo de cabeza correspondió a esta imagen - aunque la unión originaria estrecharía más los lazos entre la escultura mayor ibérica y la griega, al indicarnos la capacidad de adopción por parte del mundo ibérico de elementos iconográficos ajenos, patentes, por ejemplo, en el peinado- sino el tratar de demostrar que el atuendo reflejado en la figura de Verdolay es el que corresponde, en la plástica ibérica, a un varón y no a una dama.

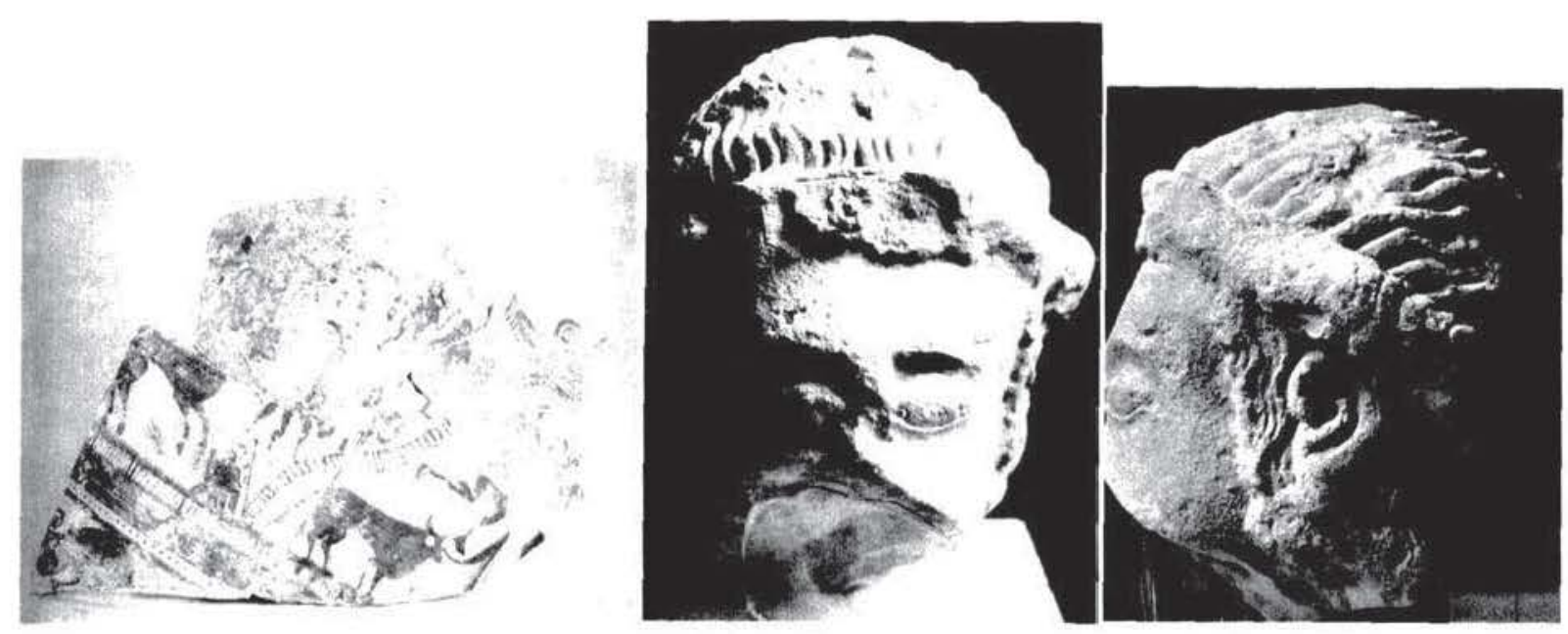

Figura 7,-Fragmento de kalathos con figura varonil sentada. Castellico de Alloza, Teruel. La silla de alto respaldo es signo de alto rango, quizá relacionado con la posesión de ganado vacuno. Museo de Teruel. Figura 8-9.-Cabeza masculina en piedra del Cabecico del Tesoro de Verdolay, hallada en 1955. Museo Arqueológico de Murcia.

afirma que la pieza se acerca cronológicamente a sus modelos, siendo éstos de la primera mitad del siglo v, y aquélla de la segunda (Op. cit. en nota 24 , T.II, pp. 141-3).

${ }_{77}$ M. Jorge Aragoneses, op. cit. en nota 13, p. 40; M. Tarradell, Imagen del Arte Iberico, 1977. figs. 17-18; E. Ruano, op. cit. en nota 24, T. II, pp. 57-58, lám. CLVIII, fig. 46, N. Cat. MU-4.

${ }^{78}$ F. Quesada, op. cit. en nota 2, T. 1, pp. 35-7. 
La adscripción al género masculino de la figura sedente del Cabecico del Tesoro de Verdolay, basada en el atuendo varonil con el que ha sido representada, deja abierta la posibilidad de considerar también como masculinos nuevos testimonios de figuras sedentes para los que no pueda argüirse un seguro carácter femenino. Igualmente supone la necesidad de reconsiderar viejos testimonios no del todo claros. En el capitulo de «dudosas" seria de rigor incluir, de momento, las piezas muy fragmentadas o deterioradas, como la procedente de Porcuna o la mal conocida "Dama de Vizcarra" ${ }^{79}$, cuyo dibujo, lo único conservado de ella (fig. $10)$, muestra una sugestiva semejanza con el plegado de los paños de la aquí estudiada. Sería aconsejable, pues, no sólo rescatar del catálogo de damas sedentes a la estatua de Verdolay, sino también abrir un nuevo apartado en el estudio de la plástica ibérica bajo el epigrafe de «varones sedentes».

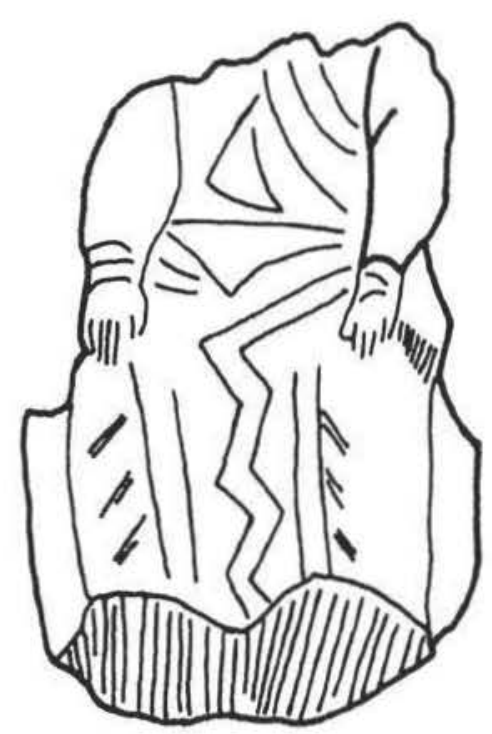

Figura 10.-«Dama de Vizcarra», según un dibujo de E. Albertini (1935).

79 E. Albertini, "Sculptures ibériques méconnues", Anuario del Cuerpo Facultativo de Archivos, Bibliotecas y Museos. Homenaje a Mélida, 1935, pp. 275 y ss.; E. Llobregat, op. cit. en nota 38, pp. 151-52, fig. 90, núm. 17. 